\title{
The neuropsychiatric disorder in systemic lupus erythematosus: evidence for both vascular and immune mechanisms
}

\author{
B. BRESNIHAN, ${ }^{1}$ R. HOHMEISTER, ${ }^{1} \mathrm{~J}$. CUTTING, ${ }^{2}$ R. L. TRAVERS, ${ }^{1}$ \\ M. WALDBURGER, ${ }^{1}$ C. BLACK, ${ }^{1}$ T. JONES, ${ }^{3}$ AND G. R. V. HUGHES
}

From the ${ }^{1}$ Department of Medicine (Rheumatology Unit), the ${ }^{2}$ Department of Psychological Medicine, and the ${ }^{3}$ Medical Research Council Cyclotron Unit, Royal Postgraduate Medical School, Hammersmith Hospital, London

SUMMARY As part of a prospective survey of systemic lupus erythematosus (SLE) a detailed collaborative study of the clinical, psychiatric, and laboratory features in 15 patients with nonfocal neuropsychiatric disease has been undertaken. In addition to conventional clinical and psychometric evaluation, electroencephalograph, and cerebrospinal fluid analysis, the study included the assessment of cerebral blood flow with oxygen-15 brain scans and serological testing for the presence of antineuronal and lymphocytotoxic antibodies. Of the 15 patients 12 had psychiatric manifestations, while 13 had various neurological abnormalities. All except 2 episodes of cerebral disease were transient. Striking abnormalities in cerebral blood flow and metabolism were seen in 12 patients, even in the presence of subtle clinical features. Sequential scans showed that improvement in clinical features was accompanied by a reversal of scan abnormalities. All sera contained brain-reactive antibody, either antineuronal IgG antibody (13) or lymphocytotoxic IgM antibody (12) or both (10), though there was an inconsistent association between clinical features and antibody titre. It is suggested that transient disturbances of cerebral vascular function in SLE might allow brainreactive antibodies from the circulation access to cerebral tissue. In this way the nature of the neuropsychiatric abnormalities would depend on both vascular and immunopathogenic mechanisms.

Clinical evidence of cerebral involvement occurs in up to $60 \%$ of patients with systemic lupus erythematosus(SLE)(Estesand Christian, 1971; Lee et al.,1977; Grigor et al., 1978). The cerebral manifestations include a wide range of neurological and psychiatric features which are frequently transient and do not result in a residual organic defect. Histological examination of post-mortem specimens has shown that the most frequent abnormalities in the brain were in the microvasculature, although actual vasculitis was uncommon (Johnson and Richardson, 1968). Clinical studies utilising technetium-99 pertechnetate brain-scanning (Bennahum et al., 1974), computed tomography (Bilaniuk et al., 1977), and more recently, ${ }^{15} \mathrm{O}$-scanning (Pinching et al., 1978) have also shown disturbances in the cerebral vasculature.

Accepted for publication 2 October 1978

Correspondence to Dr G. R. V. Hughes, Rheumatology Unit, Department of Medicine, Royal Postgraduate Medical School, Hammersmith Hospital, Du Cane Road, London W12 0HS.
In addition to the cerebrovascular lesions there is evidence that immunological mechanisms may be involved. The demonstration of lowered cerebrospinal fluid $\mathrm{C}_{4}$ (Hadler et al., 1973; Lindstrom and Sjoholm, 1975) and IgG levels (Levin et al., 1972), and of immunoglobulin and complement deposits in the choroid plexus of patients with SLE, suggested the possibility of an immunopathological process analogous to that seen in lupus nephritis (Atkins et al., 1972). Cold-reactive lymphocytotoxic IgM antibodies that bind to brain tissue have been observed in SLE sera, particularly in patients with cerebral manifestations (Butler et al., 1972; Bluestein and Zvaifler, 1976; Bresnihan et al., 1977). In addition, nonlymphocytotoxic antineuronal antibodies which cross-react with erythrocytes and are predominantly IgG have been demonstrated in the sera of patients with active cerebral involvement (Bresnihan et al., 1979).

The present study was undertaken to investigate the relative importance of vascular and immunological mechanisms during episodes of neuropsychiatric 
disease in SLE. Cerebral blood flow and circulating antibodies with nervous tissue reactivity were measured in selected SLE patients during definite episodes of neuropsychiatric disease and in whom other possible causes of cerebral disease were absent.

\section{Materials and methods}

\section{PATIENTS}

Fifteen patients with SLE were selected on the basis of having definite neurological or psychiatric complications. All were investigated during the acute phase of neuropsychiatric disease. None was receiving more than $20 \mathrm{mg}$ prednisone daily, or had hypertension, uraemia, or intracranial infection during the period of study. The diagnosis of SLE was supported in each case by the presence of at least 4 of the ARA criteria suggested by Cohen et al. (1971) and by the presence of anti-DNA antibodies (Pincus et al., 1968) in the serum at some time during their disease. In addition to general physical examination each patient was assessed for the presence of organic psychiatric manifestations which might have resulted from cerebral involvement.

In this way each patient was assigned to one of the following categories (1) acute brain syndrome, in which the features persisted less than 1 month and which either resulted in (a) cognitive impairment and psychosis, as defined by the presence of delusions and/or hallucinations, or (b) cognitive impairment alone, when the patient was not disorientated but a significant deficit attention and memory was present; (2) chronic brain syndrome, as defined by the persistence of cognitive impairment for a period greater than 1 month; (3) depressive illness, characterised by the presence of abnormal effect with self-depreciation and either sleep or appetite disturbance in the absence of psychotic features; (4) normal, where there was no evidence of psychiatric disturbance.

\section{NEUROLOGICAL INVESTIGATIONS}

These included examination of cerebrospinal fluid (CSF), electroencephalography (EEG), and ${ }^{15} \mathrm{O}$ brain scanning. CSF was examined for the presence of organisms, cells, total protein, and IgG levels. The EEG was a standard 18-electrode recording incorporating hyperventilation and photic stimulation. The following features were noted: (1) within normal limits; (2) diffuse increase of slowwave activity; (3) bursts of sharp and slow waves. Asymmetric abnormalities were also noted. Assessment of cerebral blood flow was made by brain scanning following the inhalation of tracer amounts of ${ }^{15} \mathrm{O}$-labelled carbon dioxide $\left(\mathrm{C}^{15} \mathrm{O}_{2}\right)$ Lenzi et al., 1978). After a period of equilibration the brain was scanned with a gamma camera positioned to view the lateral aspect of the head. The side studied was either the dominant hemisphere or the hemisphere indicated by clinical features, and the image produced represented regional cerebral blood flow.

SEROLOGICAL INVESTIGATIONS

All sera were examined for the presence of antineuronal antibodies and lymphocytotoxic antibodies. Antineuronal antibodies which cross-react with fetal erythrocytes were measured as previously described (Bresnihan et al., 1979). Serum was diluted 1:2 in phosphate-buffered saline (PBS) and $1 \mathrm{ml}$ incubated with $0.5 \mathrm{ml}$ washed fetal erythrocytes for 60 min at $4^{\circ} \mathrm{C}$. The cells were washed in PBS at $4^{\circ} \mathrm{C}$ before incubation in $1 \mathrm{ml}$ PBS for $60 \mathrm{~min}$ at $37^{\circ} \mathrm{C}$. After centrifugation the supernatant containing antibody eluted at $37^{\circ} \mathrm{C}$ was examined for antineuronal activity by indirect immunofluorescence on cryostat sections of normal human brain. Eluates demonstrating positive neuronal inmunofluorescence were diluted by 1 in 10 and thereafter by doubling dilutions in order to determine the highest dilution showing antineuronal activity.

Lymphocytotoxic antibodies were measured by the 2-stage microcytotoxicity assay (Mittal et al., 1968). All sera were tested simultaneously with lymphocytes from 10 normal donors. The initial $30 \mathrm{~min}$ incubation was at $4^{\circ} \mathrm{C}$, and after the addition of complement the incubation was continued for a further 3 hours at $15^{\circ} \mathrm{C}$. The lymphocytotoxicity was determined by phase-contrast microscopy and expressed as the mean percentage of donor lymphocytes killed by each serum.

\section{Results}

\section{CLINICAL FEATURES}

The general features of the 15 patients studied are listed in Table 1. All were female and their ages ranged between 16 and 52 years (mean 32.7). Nine had previous episodes of neuropsychiatric involvement which followed the onset of SLE. In 2 patients studied the cerebral episodes were present at the onset of the disease. All patients showed either haematological or serological evidence of generalised disease activity at the time neuropsychiatric features were present. Twelve patients had lymphopenia $\left(<1200 / \mathrm{mm}^{3}\right), 14$ had raised anti-DNA antibodies $\left(>30 \%\right.$, Farr assay), and 8 had decreased $\mathrm{C}_{3}$ levels ( $<60 \%$ normal). An EEG was performed on 13 patients during the acute phase of cerebral involvement. Of these, 4 were within normal limits. Nine demonstrated a diffuse increase in slow-wave activity, of which 3 were asymmetric. Two showed additional bursts of symmetric slow and sharp waves. Ten patients were receiving corticosteroids in doses 
Table 1 Details of patients with systemic lupus erythematosus

\begin{tabular}{|c|c|c|c|c|c|c|c|c|c|c|}
\hline Patient & Sex & $\begin{array}{l}\text { Age } \\
(y r)\end{array}$ & $\begin{array}{l}\text { Disease } \\
\text { duration } \\
(y r)\end{array}$ & $\begin{array}{l}\text { Previous } \\
\text { cerebral } \\
\text { involvement }\end{array}$ & $\begin{array}{l}\text { Lymphocyte } \\
\text { count } \\
\left.\text { (per } \mathrm{mm}^{3}\right)^{*}\end{array}$ & $\begin{array}{l}D N A- \\
\text { binding } \\
(\%) \dagger\end{array}$ & $\begin{array}{l}C^{3} \ddagger \\
(\%)\end{array}$ & $E E G \S$ & $\begin{array}{l}\text { Prednisone } \\
\text { dosage } \\
\text { (mg/day) }\end{array}$ & $\begin{array}{l}\text { Duration } \\
\text { steroids } \\
(y r)\end{array}$ \\
\hline 1 & $\mathbf{F}$ & 38 & 5 & + & 1220 & 89 & 51 & 0 & 10 & $1 \cdot 5^{* *}$ \\
\hline 2 & $\mathbf{F}$ & 22 & 2 & - & 300 & 99 & 48 & $1 a$ & 0 & - \\
\hline 3 & $\mathbf{F}$ & 37 & 15 & + & 1300 & 96 & 38 & $1 \mathrm{a}$ & 0 & - \\
\hline 4 & $\mathbf{F}$ & 50 & 3 & + & 1450 & 99 & 38 & 0 & 10 & 2 \\
\hline 5 & $\mathbf{F}$ & 44 & 2 & - & 270 & 18 & 100 & 1 & 0 & - \\
\hline 7 & $\mathbf{F}$ & 52 & - & - & 280 & 52 & 32 & la & 0 & - \\
\hline 8 & $\mathbf{F}$ & 29 & 4 & + & 400 & 58 & 62 & ND॥ & 5 & 4 \\
\hline 9 & $\mathbf{F}$ & 35 & 10 & + & 750 & 82 & 74 & 1 & $7 \cdot 5$ & 8 \\
\hline 10 & $\mathbf{F}$ & 28 & $1 \cdot 5$ & - & 320 & 82 & 78 & 0 & 5 & 1 \\
\hline 11 & $\mathbf{F}$ & 27 & $1 \cdot 3$ & + & 680 & 94 & 26 & 0 & $17 \cdot 5$ & 0.5 \\
\hline 12 & $\mathbf{F}$ & 31 & 21 & + & 175 & 96 & 64 & 1 & 15 & 21 \\
\hline 13 & $\mathbf{F}$ & 27 & 8 & - & 860 & 94 & 74 & ND & 0 & - \\
\hline 14 & $\mathbf{F}$ & 16 & 3 & + & 510 & 48 & 38 & 1,2 & 10 & $1 * *$ \\
\hline 15 & $\mathbf{F}$ & 38 & 18 & + & 570 & 52 & 140 & 1,2 & 10 & 0.1 \\
\hline
\end{tabular}

* Normal lymphocyte count greater than 1200 per $\mathrm{mm}^{3}(1 \cdot 2 \times 109 / 1)$.

+ Normal DNA-binding value less than $30 \%$.

$\mp$ Normal $C^{3}$ level greater than $60 \%$ level in pooled normal sera.

$\S 0=$ within normal limits; $1=$ diffuse increase slow-wave activity; $2=$ bursts of sharp and slow waves; $a=$ asymmetry.

ND $=$ not done.

** Patient also receiving azathioprine.

ranging between 5 and $17.5 \mathrm{mg}$ daily. Two patients were receiving azathioprine in addition to corticosteroids.

Twelve patients had definite psychiatric features (Table 2). An acute transient organic brain syndrome was present in 6 and in 4 of these was associated psychotic features. A chronic organic brain disorder with cognitive impairment persisting for more than 1 month was present in a further 2 patients. Four additional patients had a transient and fluctuating depressive illness without psychosis. Three patients had no evidence of any psychiatric abnormality. The neurological features are listed in Table 3. These were present in various combinations with

Table 2 Psychiatric disorders in patients with systemic lupus erythematosus

\begin{tabular}{ll}
\hline Psychiatric disorder & Number \\
\hline Depressive illness & 4 \\
Acute brain syndrome & \\
$\quad$ (with psychosis) & 4 \\
$\quad$ (without psychosis) & 2 \\
Chronic brain syndrome & 2 \\
None & 3 \\
Total & 15 \\
\hline
\end{tabular}

Table 3 Neurological features in patients with systemic lupus erythematosus

\begin{tabular}{ll}
\hline Neurological feature & Number \\
\hline Headache (nonmigrainous) & 6 \\
Headache (migrainous) & 6 \\
Dizziness/unsteadiness & 4 \\
Convulsions & 4 \\
Movement disorders & 3 \\
Cranial nerve lesions & 3 \\
Hyperreflexia & 2 \\
None & 2 \\
\hline
\end{tabular}

the psychiatric features. Headache, either migrainous or non-migrainous was the most frequent and present in 12. Four patients complained of frequent attacks of dizziness or unsteadiness. Four patients had grand mal convulsions, and an additional 3 had movement disorders such as tremor or choreiform movements. Three patients had cranial nerve lesions, 2 had hyperreflexia, 1 with bilateral extensor plantar responses. Only 2 patients, both with an acute brain syndrome, had no associated neurological abnormalities. None of the patients had pareses, peripheral neuropathy, or papilloedema. During the subsequent period of follow-up in hospital no patient developed uraemia, hypertension, cardiac failure, or intracranial infection. Seven CSF specimens were obtained. None of the 7 patients was febrile, and each specimen was sterile and without elevation of the leucocyte count (Table 4). However, in 6 the total protein content was elevated (greater than $0.6 \mathrm{~g} / \mathrm{l}$ ), and in 3 the IgG level was raised

Table 4 Cerebrospinal fluid abnormalities associated with neuropsychiatric manifestations

\begin{tabular}{lllll}
\hline Patient & $\begin{array}{l}\text { Leucocytes } \\
\left(\text { per } \text { mm }^{3}\right)\end{array}$ & $\begin{array}{l}\text { Protein } \\
(\mathrm{g} / \text { litre })^{*}\end{array}$ & $\begin{array}{l}\text { IgG } \\
(\mathrm{g} / \text { litre })\end{array}$ & $\begin{array}{l}\text { IgG/total } \\
\text { protein }(\%) \ddagger\end{array}$ \\
\hline 1 & 0 & 0.38 & 0.06 & 16 \\
4 & 2 & 0.46 & 0.12 & 26 \\
5 & 0 & 0.65 & 0.09 & 14 \\
9 & 2 & 0.63 & 0.06 & 10 \\
10 & 0 & ND§ & 0.02 & - \\
14 & 0 & 0.57 & ND & -14 \\
15 & 0 & 0.95 & 0.13 & 14 \\
\hline
\end{tabular}

* Normal CSF protein less than $0.4 \mathrm{~g} / 1$.

+ Normal CSF IgG less than $0.06 \mathrm{~g} / 1$.

¥ Normal CSF IgG/total protein less than $15 \%$.

$\S \mathrm{ND}$, not done. 
(greater than $0.06 \mathrm{~g} / \mathrm{l})$. The IgG to total protein ratio was raised $(>15 \%)$ in 2 specimens.

CEREBRAL BLOOD FLOW

${ }^{15} \mathrm{O}$-brain scans were performed on 13 patients at the time neuropsychiatric features were present. Definite

Table 5 Cerebrovascular and immunological abnormalities associated with neuropsychiatric manifestations

\begin{tabular}{|c|c|c|c|}
\hline Patient & $\begin{array}{l}15 O \text {-scan } \\
\text { defect }\end{array}$ & $\begin{array}{l}\text { Immunologica } \\
\text { Antineuronal } \\
\text { antibodies } \dagger\end{array}$ & $\begin{array}{l}\text { Lymalities } \\
\text { antibodies } \ddagger\end{array}$ \\
\hline $\begin{array}{r}1 \\
2 \\
3 \\
4 \\
5 \\
6 \\
7 \\
8 \\
9 \\
10 \\
11 \\
12 \\
13 \\
14 \\
15\end{array}$ & $\begin{array}{l}++ \\
++ \\
++ \\
+ \\
++ \\
++ \\
++ \\
++ \\
++ \\
++ \\
++ \\
\text { ND } \\
++ \\
\text { ND } \\
++\end{array}$ & $\begin{array}{l}\overline{+} \\
+ \\
++ \\
++ \\
++ \\
+ \\
+ \\
+ \\
++ \\
+ \\
++ \\
+ \\
++ \\
+\end{array}$ & $\begin{array}{l}++ \\
+ \\
++ \\
++ \\
++ \\
\overline{+} \\
\overline{+} \\
++ \\
+ \\
++ \\
++ \\
++ \\
++ \\
++\end{array}$ \\
\hline
\end{tabular}

* 15O-scan defects were categorised as major $(++)$ or minor $(+)$. $\dagger$ Antineuronal antibody titre expressed as greater than $1: 20(++)$, $1: 1$ to $1: 20(+)$, or negative $(-)$.

¥ Mean lymphocytotoxicity expressed as greater than $60 \%(++)$, $20-60 \%(+)$, or less than $20 \%(-)$. abnormalities of blood flow were apparent in each. Table 5 shows that extensive defects in the flow images were present in 12 (Fig. 1), while the remaining scan showed a lesser defect clearly outside the range seen in age-matched normal individuals (Pinching et al., 1978). There was a correlation between the localisation of the scan defect and the clinical features: those patients with psychotic and behavioural abnormalities had scan defects which were most extensive in the frontal areas; those with hyperreflexia had additional abnormalities in parietal areas.

\section{IMMUNOLOGICAL FEATURES}

Table 5 also quantitates 2 brain-reactive antibodies in the sera. All contained one of the antibodies, and the majority contained both. Thus, 13 sera contained antineuronal antibody, and in 7 the titre was greater than 1 in 20 , while 12 sera contained lymphocytotoxic antibodies, of which 10 resulted in greater than $60 \%$ lymphocyte killing.

\section{SERIAL ST UDIES}

Three patients were studied before, during, and after episodes of neuropsychiatric disease (Fig. 1). In patient 15 these was a progressive improvement in psychotic manifestations over a 4-6-week period,

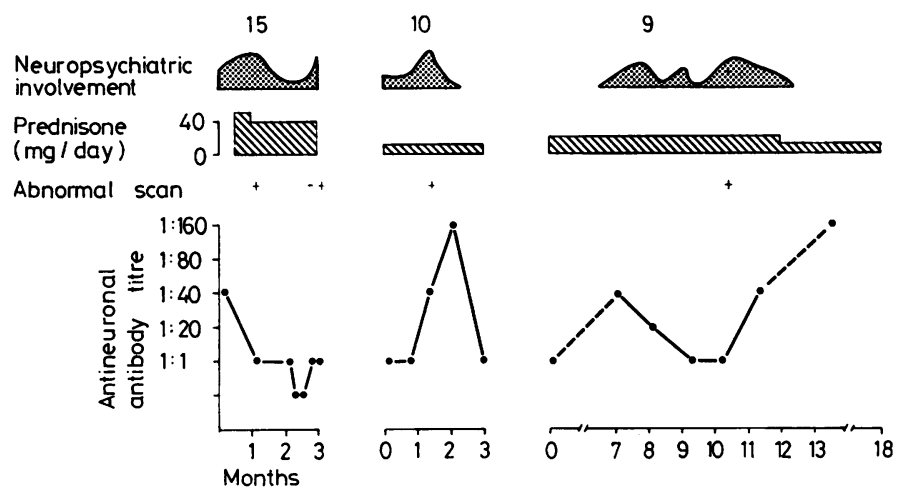

Fig. 1 Serial studies of clinical features, ${ }^{15} \mathrm{O}$-brain scan, and antineuronal antibody in 3 patients with SLE. Left, patient 15; centre, patient 10; right, patient 9 .

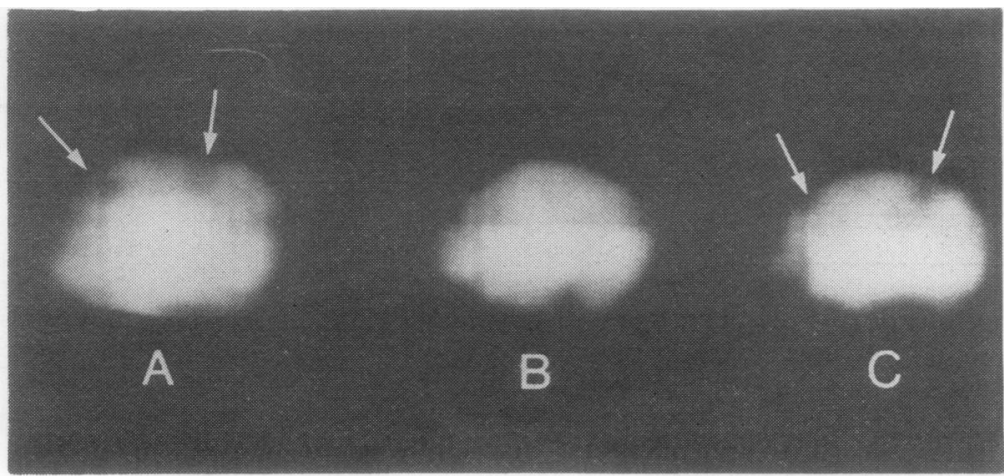

Fig. 2 Serial ${ }^{15} \mathrm{O}$-brain scans in patient 15. The frontal lobe is represented on the left side of each image. A. Abnormalities in cerebral blood flow are visible in the frontal and parietal areas (arrows). B. This scan is within normal limits. C. The abnormalities in blood flow are again visible (arrows). 
possibly in response to corticosteroid therapy. Clinical improvement was associated with a gradual decline in the titre of antineuronal antibody, and the return of the ${ }^{15} \mathrm{O}$-brain scan to normal (Fig. 2). A subsequent transient recurrence of her symptoms was associated with both an increase in antibody titre and a deterioration of the ${ }^{15} \mathrm{O}$-scan. In patient 10 a florid psychotic episode was accompanied by a rise in antibody titre, with subsequent fall following clinical remission. In the third case (9), who had a depressive illness, antineuronal antibody titre remained persistently raised, though fluctuations in titre bore no relationship to the clinical features. The ${ }^{15} \mathrm{O}$-scan showed marked abnormalities of cerebral blood flow and metabolism.

\section{Discussion}

The patients included in this study were selected because they had definite and well documented clinical evidence of neurological and/or psychiatric disease associated with SLE. That organic cerebral disease was present was further suggested by 9 out of 13 diffusely abnormal electroencephalograms and 5 out of 6 CSF specimens containing raised protein levels. All had additional laboratory evidence of active disease and were receiving either low-dose or no corticosteroid therapy at the onset of cerebral involvement. As none of the patients developed alternative reasons for cerebral disturbances, the observations described in this study may be confidently related to involvement of nervous tissues by the primary disease.

All of $13^{15} \mathrm{O}$-brain scans showed definite abnormalities of cerebral blood flow during episodes of neuropsychiatric disease. In 12 cases major defects were observed. In 13 of the 15 patients the signs of cerebral involvement did not persist, suggesting that the underlying vascular disturbances were transient. This was supported by the sequential study of patient 15 , where a return to normal of the ${ }^{15} \mathrm{O}$-scan was observed. These observations might suggest that self-limiting episodes of cerebral vasculitis, similar to those frequently observed in skin, may lead to intermittent alterations of cerebral blood flow. Thus, vascular disturbance alone may account for some of the neurological syndromes observed in SLE, as the correlation between the clinical features and the localisation of the vascular defect was generally good. However, the associations between cerebral disease and immunological abnormalities observed previously have suggested an additional process resulting in complement activation following antigen-antibody interactions (Petz et al., 1971; Atkins et al., 1972; Butler et al., 1972; Levin et al., 1972; Hadler et al., 1973; Lindstrom and Sjoholm,
1975; Bluestein and Zvaifler, 1976; Bresnihan et al., 1977; Bresnihan et al., 1979).

A possible pathogenetic role for the brainreactivity of lymphocytotoxic antibodies in cerebral lupus has been suggested (Bluestein and Zvaifler, 1976; Bresnihan et al., 1977), because high titres of cold reactive lymphocytotoxic antibodies have been shown to be more common in SLE patients with neuropsychiatric manifestations. Moreover, those found in the CNS group were shown to be absorbed out by brain homogenates, while those in patients with cerebral features were not, suggesting that a subpopulation of brain-reactive antibodies might exist (Bresnihan et al., 1977).

More recent studies have shown a further crossreactivity between cold reactive lymphocytotoxic antibodies and fetal red blood cells (Goldberg et al., 1978). Eluates prepared by rewarming the fetal red blood cells previously absorbed with SLE serum at $4^{\circ} \mathrm{C}$ have demonstrated an IgG, warm reactive antibody with strong antineuronal activity on immunofluorescence of brain preparations. In preliminary studies this antineuronal antibody has been found only in patients with SLE and cerebral involvement and was not detectable in the serum of patients with brain injury or other neurological diseases (Bresnihan et al., in press). In the present study each of the 15 sera contained either one or both antibodies; antineuronal antibody was present in 13 and lymphocytotoxic antibody in 12. The sequential studies demonstrated a relationship between antineuronal antibody titres and clinical features, though in some instances antineuronal activity persisted in the serum after the recovery of the neuropsychiatric disturbances.

Similar observations have been made during serial studies of lymphocytotoxic antibodies in SLE, where the lymphocytotoxicity was occasionally decreased at times of active neuropsychiatric disease (Bresnihan et al., in press). Therefore neither the titre of antineuronal antibody nor the degree of lymphocytotoxicity alone appears to determine the extent of the neuropsychiatric disturbance.

It is likely that other factors which might influence the leakage of antibodies across the blood-brain barrier are of major importance. It is of interest that studies utilising both technetium-99 pertechnetate (Bennahum et al., 1974) and ${ }^{15} \mathrm{O}$-brain scans (Pinching et al., 1978) have demonstrated a good correlation between cerebrovascular disorders and clinical features. It is suggested, therefore, that the events which result in often transient disease of the cerebral vasculature may allow serum antibodies with brain reactivity to gain access to cerebral parenchymal structures. In this way an immunological process might be initiated with variable effects on 
cerebral function. The present study suggests that the pathogenesis of many non-focal neuropsychiatric disorders, such as were seen in this selected group of patients, involves both vascular disease and brainreactive antibodies.

\section{References}

Atkins, C. J., Kondon, J. J., Quismoria, F. P., and Fridou, G. J. (1972). Choroid plexus in systemic lupus erythematosus. Annals of Internal Medicine, 76, 65-72.

Bennahum, D. A., Messner, R. P., and Shoop, J. D. (1974). Brain scan findings in central nervous system involvement by lupus erythematosus. Annals of Internal Medicine, 81, 763-765.

Bilaniuk, L. T., Patel, S., and Zimmerman, R. A. (1977). Computed tomography in systemic lupus erythematosus. Radiology, 124, 119-121.

Bluestein, H. G., and Zvaifler, N. J. (1976). Brain-reactive lymphocytotoxic antibodies in the serum of patients with systemic lupus erythematosus. Journal of Clinical Investigation, 57, 509-516.

Bresnihan, B., Oliver, M., Grigor, R., and Hughes, G. R. V. (1977). Brain reactivity of lymphocytotoxic antibodies in systemic lupus erythematosus with and without cerebral involvement. Clinical and Experimental Immunology, 30, 333-337.

Bresnihan, B., Oliver, M., Williams, B., and Hughes, G. R. V. (1979). Antineuronal antibody cross-reactions with erythrocytes and lymphocytes in systematic lupus erythematosus. Arthritis and Rheumatism, 22, 313-320.

Bresnihan, B., Grigor, R., Oliver, M., and Hughes, G. R. V. (In press). Lymphocytotoxic antibodies in systemic lupus erythematosus - their clinical significance. Journal of Clinical Pathology.

Butler, W. T., Sharp, J. T., Rossen, R. D., Lidsky, M. D., Mittal, K. K., and Gard, D. A. (1972). Relationship of the clinical course of systemic lupus erythematosus to the presence of circulating lymphocytotoxic antibodies. Arthritis and Rheumatism, 15, 231-238.

Cohen, A. S., Reynolds, W. E., and Franklin, E. C. (1971). Preliminary criteria for the classification of systemic lupus erythematosus. Bulletin on Rheumatic Diseases, 21, 643648.

Estes, D., and Christian, C. L. (1971). The natural history of systemic lupus erythematosus by prospective analysis. Medicine, 50, 85-95.
Goldberg, L. S., Bresnihan, B., and Hughes, G. R. V. (1978). Lymphocytotoxic antibodies in systemic lupus erythematosus: evidence for reactivity with $\mathrm{i}$ antigen. Clinical and $\overline{\mathrm{O}}$ Experimental Immunology, 31, 443-447.

Grigor, R., Edmonds, J., Lewkonia, R., Bresnihan, B., and Hughes, G. R. V. (1978). Systemic lupus erythematosus. A prospective analysis. Annals of the Rheumatic Diseases, 37, 121-128.

Hadler, N. M., Gerwin, R. D., Frank, M. M., Whitaker, J. N., Baker, M. and Decker, J. L. (1973). The fourth की component of complement in the cerebrospinal fluid in $\overrightarrow{0}$ systemic lupus erythematosus. Arthritis and Rheumatism, 16, 507-521.

Johnson, R. T., and Richardson, E. P. (1968). The neurological manifestations of systemic lupus erythematosus. Medicine, 47, 269-335.

Lee, P., Urowitz, M. B., Bookham, A. A. M., Koohler, B. E., Smythe, H. A., Gordon, D. A., and Ogryzlo, M. A. (1977). Systemic lupus erythematosus. Quarterly Journal of Medicine, 46, 1-32.

Lenzi, G. L., Jones, T., McKenzie, C. G., Buckingham, P. D., Clark, J. C., and Moss, S. (1978). Study of regional cerebral 윽 metabolism and blood flow relationships in man using the method of continuously inhaling oxygen-15 and oxygen $D$ 15 labelled carbon dioxide. Journal of Neurology, Neurosurgery, and Psychiatry, 41, 1-10.

Levin. A. S., Fudenberg, H. H., Petz, L. D., and Sharp, G. C. (1972). IgG levels in cerebrospinal fluid of patients with central nervous systemic manifestations of systemic lupus erythematosus. Clinical Immunology and Immunopathology, $1,1-5$.

Lindstrom, F. D., and Sjoholm, A. G. (1975). Cerebrospinal fluid changes in systemic lupus erythematosus with and without central nervous system involvement. Arthritis and Rheumatism, 18, 413-414 (abstract).

Mittal, K. K., Mickey, M. R., and Signal, O. P. (1968). Serotyping for immunotransplantation XVIII. Refinement of micro-droplet lymphocytotoxicity test. Transplantation, 6, 913-927.

Petz, L. D., Sharp, G. C., Cooper, N. R., and Irvin, W. S. (1971). Serum and cerebral spinal fluid complement and serum autoantibodies in systemic lupus erythematosus. Medicine, 50, 259-275.

Pinching, A. J., Travers, R. L., Hughes, G. R. V., Jones, T., and Moss, S. (1978). Detection of cerebral involvement in SLE using oxygen-15 brain scanning. Lancet, 1, 898-901.

Pincus, T., Scur, P. H., Rose, J. A., Decker, J. L., and Talal, N. (1968). Measurement of serum DNA-binding activity in systemic lupus erythematosus. New England Journal of $\mathrm{O}$ Medicine, 281, 701-705. 